\title{
COVID-19 Associated Imported Plasmodium vivax Malaria Relapse: First Reported Case and Literature Review
}

\author{
Zubair Shahid (1D \\ Nadia Karim' \\ Fakhar Shahid $\mathbb{D}^{2}$ \\ Zohaib Yousaf $\mathbb{D}^{1,3}$
}

'Internal Medicine, Hamad Medical Corporation, Doha, Qatar; ${ }^{2}$ General Surgery, Hamad Medical Corporation, Doha, Qatar; ${ }^{3}$ Dresden International University, Dresden, Germany
Correspondence: Zubair Shahid Hamad Medical City, Hamad General Hospital, Doha, 3050, Qatar Tel +974-33009959

Email Zubair.shahid.ch@gmail.com

\begin{abstract}
Plasmodium vivax ( $P$. vivax) is a protozoan parasite that causes vivax malaria. Disease relapse post-treatment is reported in $P$. vivax co-infection with other bacterial and parasitic infections, but Plasmodium vivax reactivation is not very common with viral infections. Early recognition and diagnosis of a Plasmodium vivax malaria relapse in a nonendemic region pose a diagnostic dilemma. COVID-19 co-infection compounds this dilemma due to overlapping symptoms. Early diagnosis and treatment are essential for a favorable clinical outcome. We report a middle-aged gentleman with high-grade fever and headaches who had COVID-19 and was found to have a relapse of Plasmodium vivax malaria.
\end{abstract}

Keywords: SARS-CoV-2, fever, headaches, reactivation, co-infection

\section{Introduction}

Novel coronavirus 2019 has created the COVID-19 pandemic with a spectrum of illness from asymptomatic to multiorgan dysfunction and death. Although the predominant symptoms of COVID-19 are respiratory, causing fever, flu-like symptoms, cough, shortness of breath, it can virtually affect any organ system and can have atypical presentations. ${ }^{1-4}$

Plasmodium vivax is one of the leading causes of febrile illness in endemic areas of Asia, Central America, South America, and Africa. Malaria relapses characterize P. vivax infections due to dormant parasite in the liver known as hypnozoites. ${ }^{5}$ These hypnozoites can be activated by a systemic illness or, in some cases, by other infectious diseases like salmonella typhi. ${ }^{6}$ We report a case of $P$. vivax malaria relapse associated with a COVID-19 (viral illness) co-infection, suggesting a possible role of COVID-19 in inducing current malarial relapse.

\section{Case Presentation}

A 55-year-old Indian gentleman with a medical history of type 2 diabetes mellitus presented with 5 days of dry cough, high-grade fever, chills, rigors, profuse sweating, and lethargy. There was no chest pain, palpitations, hemoptysis, rash, nausea, vomiting, diarrhea, or alteration in the consciousness level. He reported a history of $P$. vivax malaria in India 1 year back, treated successfully with artemether and lumefantrine, followed by primaquine. There was no history of recent travel, insect bites, contact with animals, or blood transfusions. Relevant history and review of systems were unremarkable. 
He was febrile (39.9 degree Celsius), tachycardiac (136 beats per minute), but had no tachypnea (18 breaths per minute), a normal blood pressure (120/ $80 \mathrm{~mm} \mathrm{Hg}$ ) and was maintaining oxygen saturation of $97 \%$ on room air. Examination revealed pharyngeal and tonsillar erythema without any exudates. There was no lymphadenopathy. The chest, abdominal and neurological examinations were within normal limits. Meningeal signs were absent.

Laboratory workup revealed neutrophilic leukocytosis (Table 1). The chest X-ray was within normal limits. Considering the febrile illness and high-pretest probability for COVID-19 based on recent exposure, a nasopharyngeal swab was sent for Genexpert reverse transcriptase-polymerase chain reaction (RT-PCR) for COVID-19 and was found to be positive. A working diagnosis of mild COVID-19 upper respiratory tract infection was made. The patient was started on treatment based on the local COVID-19 management protocol at the time.

After treatment for 3 days, there was resolution of cough and pharyngeal erythema, however, on the 4th day patient started to spike high-grade fever of 39.1 degree Celsius. Sepsis screen was ordered. The blood cultures were negative. A blood smear was done to rule out malaria. Blood smears showed ring and trophozoites of P. vivax at $0.1 \%$ (Figure 1).

Malarial treatment with Artemether/Lumefantrine four tablets twice daily was initiated. Over the next 10 days, his symptoms resolved, and he was discharged from the designated COVID-19 facility. He received the Artemether/ Lumefantrine for a total of 3 days, followed by 14 days of primaquine after ruling out G6PD deficiency, and was completely asymptomatic on 6 weeks follow-up in infectious disease clinic.

Table I Laboratory Results

\begin{tabular}{|l|l|l|}
\hline Laboratory Tests & Value & Reference Range \\
\hline White cell count & $14.8 \times 10^{3} / \mu \mathrm{L}$ & $4 \times 10^{3} / \mu \mathrm{L}-10 \times 10^{3} / \mu \mathrm{L}$ \\
Absolute neutrophil & $12.1 \times 10^{3} / \mu \mathrm{L}$ & $2 \times 10^{3} / \mu \mathrm{L}-7 \times 10^{3} / \mu \mathrm{L}$ \\
count & & \\
CRP & $88.4 \mathrm{mg} / \mathrm{L}$ & $<5 \mathrm{mg} / \mathrm{L}$ \\
Platelets & $52 \times 10^{3} / \mu \mathrm{L}$ & $150 \times 10^{3} / \mu \mathrm{L}-400 \times 10^{3} / \mu \mathrm{L}$ \\
Hematocrit & $37.0 \%$ & $40-50 \%$ \\
BUN & $3.4 \mathrm{mmol} / \mathrm{L}$ & $2.8-8.1 \mathrm{mmol} / \mathrm{L}$ \\
Creatinine & $83 \mu \mathrm{mol} / \mathrm{L}$ & $62-106 \mu \mathrm{mol} / \mathrm{L}$ \\
ALT & $19 \mathrm{U} / \mathrm{L}$ & $<40 \mathrm{U} / \mathrm{L}$ \\
AST & $18 \mathrm{U} / \mathrm{L}$ & $<40 \mathrm{U} / \mathrm{L}$ \\
Total bilirubin & $28 \mu \mathrm{mol} / \mathrm{L}$ & $<21 \mu \mathrm{mol} / \mathrm{L}$ \\
\hline
\end{tabular}

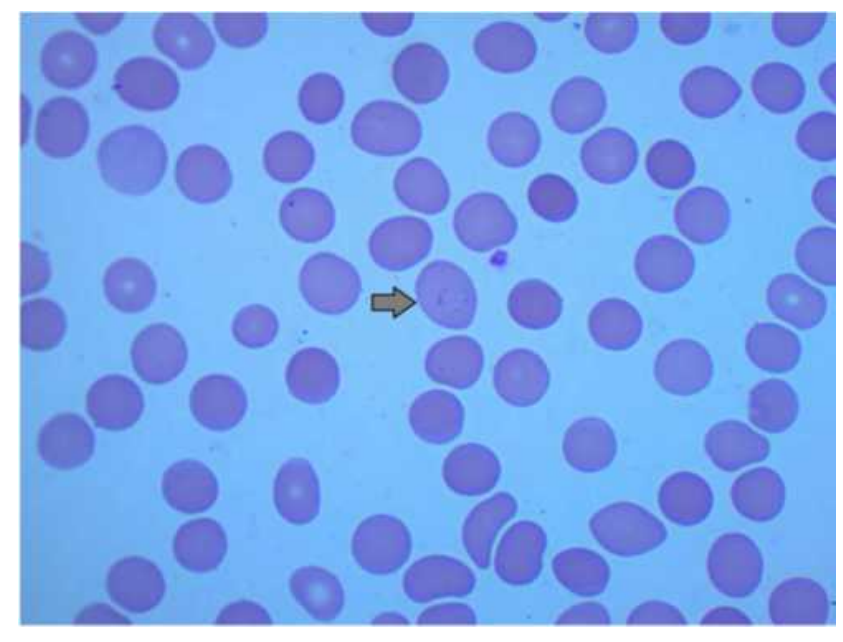

Figure I Thin malaria film showing ring-form trophozoite of $P$. vivax.

\section{Discussion}

Plasmodium vivax is an intracellular parasite transmitted to humans by the bite of a female Anopheles mosquito. $P$. vivax malaria is a significant cause of morbidity in endemic areas. $P$. vivax can relapse by the activation of dormant liver-stage hypnozoites. Multiple relapses can follow a single mosquito inoculation. ${ }^{6}$ Infections such as Plasmodium vivax or Plasmodium falciparum malaria and certain bacterial infections are associated with relapse. However, there is no evidence of a malarial vivax relapse by viral illness ${ }^{5}$ Qatar is not an endemic area of $P$. vivax; however, imported malaria represents a significant threat to eliminating malaria in this region. ${ }^{7}$

The patient has a history of $P$. vivax infection, which was treated successfully a year ago, and the patient had been symptoms free since then. He had a history of exposure to COVID-19, after which he experienced fever, headache, and cough and was diagnosed as mild COVID-19 upper respiratory tract illness. Co-infections in COVID-19 are reported but not well-studied ${ }^{8}$; however, the persisting fever and malaria history raised suspicion of relapse due to COVID-19 infection. The patient received early treatment and made a complete clinical recovery.

The authors reviewed the literature on PubMed. Keywords used were (Plasmodium vivax) AND ((COVID-19) OR (SARS-CoV-2) OR (viral illness) OR (virus)). The search duration was from 1940 to October 7, 2020. 235 results were obtained and screened by two authors independently. 36 articles elaborating viral coinfections were found with dengue and HIV being the most common viral co-infections (Table 2). There has been a case report of COVID-19 and Plasmodium vivax 
Table 2 A Literature Review of Plasmodium vivax Co-Infection with Viruses

\begin{tabular}{|c|c|c|c|c|}
\hline Number & Author & Type of Viral Co-Infection & PMID & Year of Publication \\
\hline I. & Santana Vdos S et al & Dengue & 21085859 & 2020 \\
\hline 2. & Kishore, $\mathrm{R}$ et al & SARS-CoV-2 & 32621173 & 2020 \\
\hline 3. & Sundus Sardar et al & SARS-CoV-2 & 32665888 & 2020 \\
\hline 4. & Crystyan Siles et al & Guaroa virus & 32186493 & 2020 \\
\hline 5. & Luís A B Cruz et al & Hepatitis B virus (HBV) & 31233500 & 2019 \\
\hline 6. & Ana Cláudia Pereira Terças-Trettel et al & Hantavirus & 31130600 & 2019 \\
\hline 7. & Montenegro-Idrogo JJ et al & HIV & 31800949 & 2019 \\
\hline 8. & Wondimeneh Y. et al & HIV & 30109850 & 2018 \\
\hline 9. & Dewanee Ranaweera et al & HIV & 30445967 & 2018 \\
\hline 10. & Gebremeskel Tekle S et al & Varicella-Zoster & $300 \mid 4823$ & 2018 \\
\hline 11. & Vikarn Vishwajeet et al & Hepatitis B & 29575054 & 2018 \\
\hline 12. & Mohapatra PK et al & HIV & 28749403 & 2017 \\
\hline 13. & Tazeen A et al & Dengue and chikunguniya & 28910810 & 2017 \\
\hline 14. & Rao MR et al & Dengue & 26653975 & 2016 \\
\hline 15. & Vitor R R Mendonça et al & Dengue & 26271921 & 2015 \\
\hline 16. & Stępień M. & Dengue & 26233086 & 2015 \\
\hline 17. & Nicola Petrosillo et al & Ebola & 26471197 & 2015 \\
\hline 18. & Rattanapunya $S$ et al & HIV & 25728746 & 2015 \\
\hline 19. & Magalhães BM et al & Dengue & 25340346 & 2014 \\
\hline 20. & Mushtaq, MB et al & Dengue & 23606854 & 2013 \\
\hline 21. & Magalhães BM et al & Dengue & 23033396 & 2012 \\
\hline 22. & Andrade, BB et al & Hepatitis B & 21625634 & 2011 \\
\hline 23. & Santana Vdos S et al & Dengue & 21085859 & 2010 \\
\hline 24. & Mclver LJ et al & HIV & $2|4| 353 \mid$ & 2010 \\
\hline 25. & Chaudhry, R. et al & Leptospirosis dengue, Hepatitis E & 19136807 & 2009 \\
\hline 26. & Abbasi, A. et al & Dengue & 19149976 & 2009 \\
\hline 27. & Kaushik R.M. et al & Dengue & 17568646 & 2007 \\
\hline 28. & Braga WS et al & Hepatitis B & 16501762 & 2006 \\
\hline 29. & Deresinski S & Dengue & 17283647 & 2006 \\
\hline 30. & Thangaratham PS et al & Dengue & 16785712 & 2006 \\
\hline 31. & Braga WS et al & Hepatitis B & $15895|7|$ & 2005 \\
\hline 32. & Bansal, $R$ et al & Hepatitis E & 12416764 & 2002 \\
\hline 33. & Katongole-Mbidde $\mathrm{E}$. et al & HIV & 3130932 & 1998 \\
\hline 34. & Hinrichsen SL. et al & HIV & 8984995 & 1996 \\
\hline 35. & Lo SS et al & HIV & 1784955 & 1991 \\
\hline 36. & Brown AE et al & Varicella-Zoster & 1658946 & 1991 \\
\hline
\end{tabular}

malaria co-infection and another with possible reactivation of $P$. vivax secondary to SARS-CoV-2 co-infection. ${ }^{9}$ This is the second reported case of reactivation of $P$. vivax associated with COVID-19 and the first case of reactivation of imported malaria associated with COVID-19 in a non-endemic area. The similarity in the non-specific symptoms and febrile illness associated with COVID-19 and malaria makes missing a malaria diagnosis in the COVID-19 pandemic highly likely. Although the exact mechanism causing this activation is unclear, cytokine response associated with systemic illness has been postulated to induce vivax malaria relapses. ${ }^{5}$
Authors believe that patients presenting with symptoms of fevers, headaches, and myalgias should be investigated for malaria infection, especially if they belong to an endemic region or have a history of malaria. Early management can decrease morbidity and mortality.

\section{Conclusion}

Co-infections in COVID-19 are reported but not wellstudied. ${ }^{9}$ Plasmodium vivax relapse should be considered a potential differential diagnosis of febrile illness in any patient with a previous malaria vivax presenting with viral illness symptoms. Delays in recognition and 
appropriate treatment of malaria can increase morbidity and mortality.

\section{Informed Consent}

Written informed consent has been provided by the patient to have the case details and any accompanying images published. It was approved by Medical Research Center - HMC.

\section{Funding}

Funds provided by Qatar National Library.

\section{Disclosure}

All authors have no conflicts of interest.

\section{References}

1. Cheung KS, Hung IFN, Chan PPY, et al. Gastrointestinal manifestations of SARS-CoV-2 infection and virus load in fecal samples from a Hong Kong Cohort: systematic review and meta-analysis. Gastroenterology. 2020;159(1):81-95. doi:10.1053/j.gastro.2020.03. 065
2. Montalvan V, Lee J, Bueso T, de Toledo J, Rivas K. Neurological manifestations of COVID-19 and other coronavirus infections: a systematic review. Clin Neurol Neurosurg. 2020;194:105921. doi:10.1016/j.clineuro.2020.105921

3. Zhai LL, Xiang F, Wang W, et al. Atypical presentations of coronavirus disease 2019 in a patient with acute obstructive suppurative cholangitis. Clin Res Hepatol Gastroenterol. 2020;44(6):e135-e140. doi:10.1016/j.clinre.2020.05.003

4. Singhania N, Bansal S, Singhania G. An atypical presentation of novel Coronavirus disease 2019 (COVID-19). Am J Med. 2020;133 (7):e365-e366. doi:10.1016/j.amjmed.2020.03.026

5 . White NJ. Determinants of relapse periodicity in Plasmodium vivax malaria. Malar J. 2011;10. doi:10.1186/1475-2875-10-297

6. Shanks GD, White NJ. The activation of vivax malaria hypnozoites by infectious diseases. Lancet Infect Dis. 2013;13(10):900-906. doi:10.1016/S1473-3099(13)70095-1

7. Farag E, Bansal D, Chehab MAH, et al. Epidemiology of malaria in the state of Qatar, 2008-2015. Mediterr J Hematol Infect Dis. 2018;10(1):e2018050. doi:10.4084/mjhid.2018.050

8. Yousaf Z, Khan AA, Chaudhary HA, et al. Cavitary pulmonary tuberculosis with COVID-19 coinfection. IDCases. 2020;22:e0973. doi:10.1016/j.idcr.2020.e00973

9. Sardar S, Sharma R, Alyamani TYM, Aboukamar M. COVID-19 and Plasmodium vivax malaria co-infection. IDCases. 2020;21:e00879. doi:10.1016/j.idcr.2020.e00879

\section{Publish your work in this journal}

Research and Reports in Tropical Medicine is an international, peerreviewed, open access journal publishing original research, case reports, editorials, reviews and commentaries on all areas of tropical medicine, including: Diseases and medicine in tropical regions; Entomology; Epidemiology; Health economics issues; Infectious disease; Laboratory science and new technology in tropical medicine;
Parasitology; Public health medicine/health care policy in tropical regions; and Microbiology. The manuscript management system is completely online and includes a very quick and fair peer-review system. Visit http://www.dovepress.com/testimonials.php to read real quotes from published authors. 